\title{
"LOCURA Y ESCÁNDALO": UN MESÍAS CRUCIFICADO Y UNA HISTORIA MARCADA POR LA CRUZ
}

\author{
"Madness and Scandal": a Crucified Messiah and a History Marked by the Cross
}

José Ignacio González Faus*

RESUMEN: La intención del artículo es hacer una revisión del mesianismo de Jesús en el contexto eclesial y político actual. Si cristianismo significa literalmente mesianismo, todo seguidor de Jesús habrá de tener una visión "mesiánica" de la historia. Lo que quiere decir que el cristiano está llamado a trabajar en la construcción de la historia. Y de hecho, cuando la historia no tiene un horizonte mesiánico degenera en una mera sociedad de consumo que acaba quitando sentido a las vidas humanas y generando reacciones extremistas violentas que, en el fondo, buscan alguna forma de mesianismo. Pero el mesianismo cristiano no es el del Primer Testamento sino el de Jesús. Y el de Jesús es un mesianismo escandaloso que pasa por la cruz. La visión cristiana de la historia estará tentada de caer en las expectativas erróneas de Pedro en Cesarea (formas diversas de milenarismo) y en la decepción final de los discípulos (tentaciones apocalípticas): con lenguaje de hoy, tentaciones de la Modernidad y de la postmodernidad. Por eso, la teología de la historia será también hoy "locura y escándalo". Pero no dejará de ser mesiánica si recupera una auténtica pneumatología y una cristología del Espíritu.

PALABRAS CLAVE: Mesías. Cruz. Milenarismo. Apocalíptica. Modernidad. Postmodernidad.

ABSTRACT: I was asked to review Jesus' messianism in the current ecclesial and political context. If Christianity literally means messianism, every follower of Jesus ought to have a "messianic" view of history, meaning that Christians are called to work on the construction of history. Indeed, when history has no

* Universidad Centroamericana José Simeón Canas, San Salvador, El Salvador. 
messianic horizon, it degenerates into a mere consumer society that renders human life meaningless and generates violent extremist reactions, ultimately, in the quest for some form of messianism. However, Christian messianism is not that of the First Testament, but that of Jesus, a scandalous, revolutionary messianism that goes through the cross. The Christian vision of history can be tempted to harbor /cultivate Peter's false expectations in Caesarea (various forms of millennialism) as well as the disciples' final disappointment (apocalyptic temptations): in today's language, temptations of Modernity and postmodernity. That is why the theology of history can also be "madness and scandal" today. However, it will not cease to be messianic if it recovers a true pneumatology and a Christology of the Spirit.

KEYWORDS: Messiah. Cross. Millenarism. Apocalyptic. Modernity. Postmodernity.

La historia es un tejido de violencia y sufrimientos del que los hombres son, a la vez, autores y víctimas, sin llegar a darle un sentido liberador. Sin duda ha sido siempre así. Pero los hombres de tiempos pasados no se sentían sujetos de la historia, no tenían modos de pensarla y dominarla, se sentían entregados a la fatalidad ciega de una historia sobre la que no tenían poder. En la Modernidad ya no es así: el hombre ha tomado conciencia de su historicidad, se siente hecho por la historia, pero también agente responsable de su propia historia. Es capaz de pensar la historia pasada y la presente. Solidario de la historia, quiere darse a sí mismo razón de ella, actuar sobre ella, tomarla en sus manos, darle un sentido. Esta conciencia nueva plantea un problema teológico nuevo, que orienta la reflexión sobre la muerte de Cristo" (MOINGT, 1993, p. 273).

\section{Introducción}

-1 propósito de este trabajo es presentar "una revisión del mesianismo $\amalg$ de Jesús, revisitado en el contexto eclesial y político global". Creo que en lo mucho (quizá demasiado) que llevo escrito, hay infinidad de elementos que pueden responder a esa petición, aunque nunca he abordado el tema así directamente. Hago esta observación porque buen parte de lo que voy a escribir aquí serán citas o repeticiones de otros escritos míos. De dos sobre todo: mi primera cristología (La Humanidad Nueva) y un artículo aparecido en el número 108 de la Revista Latinoamericana de Teología que, de todos modos, por razones del confinamiento vírico, ya no pudo ser enviado por correo. Aquel artículo se titulaba precisamente: ¿Hay una teología de la historia? Y ya se ve que lo del mesianismo tiene mucho que ver con esa posibilidad de una teología de la historia. Cuento pues con que el lector se haga cargo si constata que me repito y espero que esas repeticiones sean ahora material para construir lo que se me ha pedido. 


\section{La ambigüedad de la palabra Mesías}

\subsection{El lenguaje}

En los textos fundacionales del cristianismo ocurre algo muy paradójico con la palabra mesías. En el célebre capítulo 16 de san Mateo, el apóstol Pedro recibe de parte de Jesús una alabanza que casi parece exagerada, por confesar que Jesús es el Mesías. En el diálogo que sigue, cuando Jesús anuncia su pasión futura, Pedro le aclara que él ha hablado de un mesías no crucificado. Y entonces se encuentra con la que puede ser la más dura crítica que hay en todos los evangelios ("apártate de mí, Satanás").

Pero no es solo Pedro: cuando Pablo quiere resumir la identidad cristiana que él anuncia habla de "un mesías crucificado" $(1$ Cor 1,23). Y sin necesitar ahora el comentario de Jesús, el mismo Pablo aclara que eso es un escándalo para los piadosos y una locura para los sabios. La palabra más sagrada y más prometedora, la que mejor podía resumir toda la tradición de la que Pablo procede, se convierte ahora en una innegable piedra de tropiezo.

Para acabar de oscurecer, y de confirmar esta confusión, Jesús termina siendo condenado como Mesías ("rey de los judíos" dice el título de la cruz cuya historicidad parece innegable). Y, pese a ese final fracasado, el cuarto evangelio se cierra avisando que ha sido escrito "para que creáis que Jesús es el Mesías" (20,31).

Esta confusión no aparece en el Primer Testamento, a pesar de repetidas experiencias de fracaso (visto como castigo de Dios), y de las diferentes concreciones de la esperanza mesiánica (rey, sacerdote etc.). A pesar de todo eso, el Primer Testamento es claro testimonio de una esperanza histórica confiada. La mitad de la plegaria de los salmos (tan finamente espirituales en muchos momentos) está vuelta a la historia para constatar que en ella: "los ojos del malvado espían al pobre, mientras escondido como león en su guarida, acecha al desgraciado para robarle; se agacha y se encoge y cae con violencia sobre el indefenso". Para terminar suplicando "que el hombre hecho de tierra no vuelva a sembrar su terror"1. Si Marx quiso definir la historia como historia de la lucha de clases, el salmista se le adelanta y le supera, viéndola como historia "de la agresión" de clases. Aunque la palabra clase no tenga ahora el sentido técnico posterior.

Y la historia sigue hoy tal como la rezaba el salmista. Es por eso lógico, en este sentido, que los judíos nieguen el mesianismo de Jesús remitiendo para ello a cómo está nuestro mundo.

\footnotetext{
${ }^{1}$ Salmo 10 (9b), versos 9 y 18. Me limito a una sola cita (la primera quizás), no sin dejar constancia de que podría llenar todo el espacio que se me dio para este artículo, con citas ulteriores de los salmos en el mismo sentido y a veces mucho más duras.
} 
Pues bien: a pesar de todo eso, el título de Mesías es tan definitorio de Jesús que ha dejado de ser un título honorífico para convertirse en parte de su nombre (Jesu-cristo ${ }^{2}$ ). Otros títulos cristológicos podrán ser más honorables pero no son tan definitorios. Por eso en La Humanidad Nueva, al exponer el título de Mesías, comenté que "cristianismo significa exactamente mesianismo y cristiano quiere decir mesiánico".

Estamos ahí en pura gramática. Pero me temo que si hoy hiciéramos a los llamados cristianos, una encuesta semejante a la que hizo el Nazareno con sus discípulos, preguntándoles qué creen ser, pocos responderían en la línea de Pedro, confesándose mesiánicos. Y me temo también que la mayoría de estos pocos entendería su confesión en la línea petrina de un mesías no crucificado.

(Entre paréntesis: no quisiera con esto molestar a nadie. Sé que hay muchos cristianos excelentes en su fe y en su conducta. Pero sí me atrevería a decirles que "el traje" cristiano es el que llevan falsificado).

\subsection{Del vocablo a la historia}

Desde el presupuesto cristiano de que el Espíritu de Dios ha sido derramado "sobre toda carne", vengo repitiendo últimamente que en la historia del mundo hay tres experiencias válidas de Dios:

- Dios en la propia intimidad, como lo mejor y más hondo de mí (propia de las cosmovisiones orientales);

- Dios en la naturaleza (más típica de todo el continente americano, con figuras como la Pachamama etc.), y

- Dios en la historia (característica del mensaje cristiano y, en mi opinión, culmen de las otras dos).

Si se las quiere formular trinitariamente, podríamos hablar de una experiencia del Espíritu santificador, una experiencia del Padre creador y una experiencia de la Palabra reveladora y redentora.

He dicho también que esas tres experiencias se necesitan unas a otras: "porque una absolutización de la historia, privada de las otras dos visiones degenera en una falta de respeto a la naturaleza y en una falsificación de la actitud del hombre ante la historia, que excluirá de ella a una parte del género humano. Pero una sacralización de la naturaleza ajena a la historia irá a dar en una rendición conservadora ante la naturaleza, olvidando que la tierra no es solo "jardín" (Gn 2,8) sino que también ha de ser "hecha habitable" (Gn 1,28)3.

\footnotetext{
${ }^{2}$ Como ya es sabido, Xristós es la traducción griega del hebreo mashià (ungir) de donde viene nuestro mesías.
} 
Y la inmensa sabiduría del Oriente sorprende y desconcierta a veces por su exhortación a "no hacer nada"; por ejemplo: "practica el no-hacer, esfuérzate por no esforzarte" ${ }^{\prime 4}$ (GONZÁLEZ FAUS, 2019, p. 305-306).

Hasta tal punto, que una de las causas de la dura persecución de hoy contra los cristianos en la India es, precisamente, el esfuerzo de estos ante los parias y las castas ínfimas (desde la conocida como teología "dalit").

Pero, aun con esta unificación de las tres experiencias de Dios, la historia no pierde su importancia ni su ambivalencia. Y la ambigüedad del término mesías, que venimos analizando, culmina en que ese título que, como acabo de decir, acabó convirtiéndose en nombre de Jesús, es el que el mismo Jesús parece haber rechazado expresamente durante su vida terrena (y rechazar es algo más que solo ignorar o desconocer). En La Humanidad Nueva razoné esta afirmación, para concluir que la teología del mesianismo de Jesús puede resumirse en esta frase: “Jesús es el esperado que destruye las esperanzas" (o las expectativas, matizando un poco) (GONZÁLES FAUS, 2016, p. 306).

Pues bien: toda esta visión del mesianismo nos será ahora muy útil para volvernos a la historia humana.

\section{La historia humana entre mesianismo y apocalíptica}

A pesar de lo que acabo de decir sobre la experiencia cristiana de la divinidad como Dios en la historia, es innegable que la trayectoria del cristianismo acusa un olvido progresivo de la historia tras la inculturación en aquella Grecia, cuna de la metafísica, que carecía del sentido de la historia. La cosmovisión griega vivía abierta al ser: su absolutez parmenidiana o su fluidez heraclitana. Y ya sabemos la desazón que provocan hoy determinados términos metafísicos (consubstancial, naturaleza, subsistencia ${ }^{5}$ ) de los primeros textos cristianos, aunque sus defensores se esfuercen por mostrar que precisamente se rompe el significado de esos términos al insertarlos en los textos cristianos. Pero el problema sigue siendo que,

\footnotetext{
${ }^{3}$ Por ejemplo: desde las cumbres inhóspitas del altiplano, entre Perú y Bolivia, es imposible creer que el hombre está allí para cuidar ese jardín. Mientras que sí puede entenderse que el hombre esté allí para humanizarlo, para hacerlo habitable (que es lo que significa la palabra hebrea que solemos traducir como "dominar").

${ }^{4}$ Tao te King 3, 63. O: "si alguien pretende conquistar el mundo y hacer con él lo que quiera, no veo cómo podrá tener éxito" (29). Ver también 43 ("los frutos del no-hacer"). Esa especie de exhortación a la pasividad me parece derivar de su afán por predicar la moderación y se repite varias veces en este pequeño libro.

${ }^{5}$ Prefiero traducir así el término hypostasis porque la traducción habitual (persona) genera claros malentendidos dado el significado que esa palabra tiene para nosotros hoy, tan distinto del que tenía en la antigüedad, totalmente ajeno a lo que nosotros llamamos hoy personalismo.
} 
aunque se rompa su significado, se usan esos términos que parecen tan ajenos a la historia.

Olvidada la historia, el título de Mesías se identifica unilateralmente con el de Salvador. Y en la cristología occidental, que olvida a Jesús como revelador de Dios (para centrarse en Él sólo como Redentor), esa salvación alude únicamente al más-allá: “Jesús vino para abrirnos las puertas del cielo" aprendí de niño en el catecismo. A nadie se le ocurría entonces pensar que su venida tuviera también algo que ver con el mejorar un poco esta tierra, en continuidad con la oración de los salmos. Con este olvido de la historia, el tiempo solo es ocasión de méritos personales para conseguir el más-allá. Sin embargo el Padrenuestro pide cosas para el más-acá: sustento para todos, reconciliación, superar al mal, más un reinado de Dios en esta tierra donde debe cumplirse también la voluntad de Dios.

Este dato era importante citarlo porque, como reacción contra ese olvido, la Modernidad supuso el intento de recuperar algo muy cristiano, pero cortando el cordón umbilical que lo unía con el cristianismo: se redescubrió la historia y se pasó de "tierra para el cielo" al "cielo en la tierra"6. Hasta que Josep Ramoneda (un magnífico sociólogo español, no cristiano) comentó muy gráficamente un día que "tras haber dejado el cielo para hacer de la tierra un cielo, nos hemos quedado sin cielo y sin tierra" (GONZÁLEZ FAUS, 2019, p. 320).

Desde entonces quizá podemos afirmar que, así como el Nuevo Testamento comienza con textos mesiánicos, en los evangelios y en la primera predicación cristiana, para terminar con un Apocalipsis, también la historia humana parece moverse entre épocas mesiánicas y épocas apocalípticas ${ }^{7}$. $\mathrm{Y}$ esto pervive en Occidente fuera del cristianismo porque, como acabo de decir, la llamada Modernidad retoma contra el cristianismo aquel mesianismo histórico que la Iglesia había abandonado ${ }^{8}$. Libertad igualdad fraternidad, serán palabras muy cristianas (y así lo proclamó Juan Pablo

\footnotetext{
${ }^{6}$ Recordemos, por ejemplo, las preguntas $2^{2}$ y $3^{\underline{a}}$ de Kant: qué puedo esperar, qué tengo que hacer.

${ }^{7}$ Dando ahora a la palabra el sentido más frecuente en nuestro uso y que alude a una calamidad (recordar: Apocalipsis now) y no al sentido literal de "revelación" (de que Dios sigue estando presente en los tiempos difíciles).

${ }^{8}$ Un ejemplo de esta forma laica de "milenarismo" lo tenemos en estas palabras de Condorcet en su Esbozo de una historia del espíritu humano en plena revolución francesa: "Llegará pues el momento en que el sol sobre la tierra no iluminará más que a hombres libres que no reconocerán otro maestro que su razón; en que los tiranos y los esclavos, los sacerdotes y sus instrumentos estúpidos ya no existirán más que en la historia y en los teatros; en que nadie se ocupará de ellos más que para llorar a su víctimas y sus engaños o para dejarse guiar por el horror de sus excesos hacia una vigilancia útil para saber reconocer y ahogar bajo el peso de la razón los primeros gérmenes de la superstición y la tiranía si es que atreven a reaparecer" (CONDORCET, 1980, p. 230). Nunca dejo de preguntarme qué diría hoy ese profeta de hace más de dos siglos si pudiera comparar su profecía con nuestra situación actual.
} 
II, solo que con 200 años de retraso). Pero el hecho es que nacen y son gritadas precisamente en contra de la Iglesia, y ello a pesar de que el grito de libertad, igualdad y fraternidad, tiene una inmensa riqueza teológica: dignidad de hijos libres, hermanados en el Cristo recapitulador e igualados por el Espíritu. Pero ya afirmó Congar que, cuando la Iglesia olvida una verdad evangélica, Dios hace brotar esa verdad fuera de la Iglesia. Lo malo fue que, como he comentado otras veces, precisamente al proclamar esas grandes palabras fuera de su matriz cristiana, se abortó su contenido y se nos han convertido hoy en una libertad contra la igualdad y al margen de la fraternidad. Por eso las hemos olvidado hoy, y debería ser tarea actual de la Iglesia el recuperarlas en todo su esplendor y plenitud.

No somos pues tan originales como creemos cuando hablamos hoy de modernidad y postmodernidad: la historia ha oscilado siempre entre horas que cabría llamar mesiánicas y horas apocalípticas, entre horas optimistas y pesimistas. Incluso, aunque acabo de decir que el cristianismo al encarnarse en Grecia pierde el sentido de la historia, subsisten sin embargo amagos mesiánicos que ahora deberíamos llamar milenaristas. Aparecen primero por la promesa del Apocalipsis $(20,2-4)$ de que os justos acabarán reinando "mil años". Y luego, cuando tampoco se ve claro ese reinado de los justos en la historia profana, se traslada ese milenarismo a la Iglesia. Lo cual tuvo unas consecuencias muy negativas para la eclesiología que vale la pena evocar (aunque sea en un paréntesis) porque son muy significativas para nosotros. Ese milenarismo eclesiástico se refleja en la tácita identificación entre Iglesia y Reino de Dios:

Agustín ya se había adelantado a considerar todo el tiempo de la Iglesia como reino de Cristo y cree que, cuando este se acabe, volverán otra vez las luchas escatológicas del fin del mundo. Desde esta eclesiología, la adoración de Dios es la suprema finalidad del Estado. Lo cual sitúa al Estado en el mismo plano y por debajo de la Iglesia, y contribuye al clericalismo creciente en las iglesias, desde la idea de la sociedad como "pueblo cristiano". Así, tras la primera separación entre clero y laicos, surge ahora otra separación entre pueblo e Iglesia, y se pasa también de comunión en la Iglesia a comunión con la Iglesia9', o a la reducción de la Iglesia a la jerarquía ${ }^{10}$, a la pérdida del carácter comunitario de los sacramentos y, finalmente, a la resistencia de muchos, cuando el Vaticano II vuelve a llamar a la Iglesia "pueblo de Dios": porque así se rompía la antigua distinción entre Iglesia y pueblo...(GONZÁLEZ FAUS, 2019, p. 313)

Cerrando este paréntesis eclesiológico, debo prescindir aquí de esos chispazos "milenaristas"11, para ceñirme más a las oscilaciones de nuestra hora histórica. En la Europa desde la que escribo, nos contentamos con

\footnotetext{
${ }^{9}$ Por ejemplo: las reglas que escribió san Ignacio sobre el verdadero sentido que debemos tener en la Iglesia, se nos han convertido hoy en reglas para sentir con la Iglesia...

${ }^{10}$ El gran Yves Congar ya calificó de "jerarcología" a la eclesiología que le había precedido.

${ }^{11}$ Están comentadas en el artículo citado de la Revista Latinoamericana de Teología (n. 108).
} 
vocablos abstractos como modernidad y postmodernidad. En América Latina se puede habar más concretamente: de sandinismo y orteguismo en Nicaragua; o de Zelaya y postzelaya en la monstruosa Honduras (tan cuidadosamente silenciada por nuestros medios de comunicación); de chavismo y madurísimo en Venezuela, o de Lula y Bolsonaro en Brasil o Correa y Lenin en Ecuador... Y, con una visión históricamente más amplia, debemos hablar también de otra degradación, mucho más lenta pero igualmente innegable: la que va desde el precioso "sueño americano" de los primeros migrantes a la América del Norte, hasta el doloroso (pero innegable) "desastre manifiesto" que no deja de ser tal porque se pretenda bautizarlo como un destino providencial ${ }^{12} \ldots$

Estas evidentes oscilaciones dejan una pregunta fundamental. La historia está llamada a progresar, sí. Pero ¿progresa o ha progresado realmente? ${ }^{13}$ La respuesta a esta pregunta es lo que da lugar a actitudes más mesiánicas (¿mecánicas?, preguntarán otros) o más apocalípticas, (que sus detentores calificarán solo como más realistas, según aquel dicho thatcheriano: “there is no alternative").

Veamos pues cuál es esa situación para la que, según la señora Thatcher, no hay alternativa.

\subsection{La ambigüedad de nuestro progreso}

Tres rasgos llaman la atención cuando analizamos el progreso de nuestra historia.

a) Hegel ya había percibido asustado que nuestra la está construida sobre víctimas, para acabar justificando esa atrocidad con la excusa del progreso. Pero ¿puede llamarse progreso a lo que está construido sobre cadáveres de víctimas y de excluidos? Y además, toda nuestra presunta paz, se parece a la del antiguo imperio romano: una paz interna sostenida a base de guerras en el exterior (en Irak, en Siria, en Yemen, en Sudán, en Ruanda...), que aseguran además nuestra prosperidad económica gracias al comercio de las armas.

\footnotetext{
${ }^{12} \mathrm{Si}$ las causas de esa degradación están en la conocida tesis de M. Weber de que el miedo a la dura predestinación calvinista, lleva a considerar el éxito económico como una señal de que uno no está destinado al infierno (porque Dios no bendeciría en esta vida al que va a maldecir en la vida futura), es un tema que no toca tratar ahora. Pero sí convenía evocar esa tesis porque ahí entra en juego esa pasión por el dinero que, a la vez, parece muy típica de la cultura norteamericana, y es calificada por el Nuevo Testamento como "raíz de todos los males" (1Tim 6,10). Y eso sí que tiene algo que ver con la ambigüedad del mesianismo. ${ }^{13}$ Siglos antes de Cristo, el gran dramaturgo griego que fue Eurípides, escribía en la tragedia Hipólito: “¡Oh hombres que poseéis muchos conocimientos inútiles! ¿Por qué enseñáis innumerables técnicas y lo arregláis todo e inventáis tantas cosas, pero en cambio hay una cosa que no sabéis y que todavía no habéis descubierto: enseñar la sabiduría a los que no la poseen?" (EURÍPEDES, 1991, p. 359, v. 920).
} 
Lo que queda de nuestras izquierdas aún apela ingenuamente al progreso, desconociendo las críticas actuales a nuestro modo de progresar, hechas por figuras eximias de la izquierda, como Walter Benjamin y Simone Weil. Pero ya hace ya casi un siglo que se escribieron (desde la Europa "ilustra$\mathrm{da}^{\prime \prime}$ ) estas palabras a las que no hemos hecho demasiado caso, aceptando quizás, inconscientemente, la idea hegeliana del progreso con víctimas:

"El siglo que fue la era de la expansión de Europa, fue también con demasiada frecuencia un siglo de bárbara ceguera... Hasta ese punto nos ha hecho injustos para con los otros pueblos el orgullo de nuestras máquinas y nuestras armas; hasta ese punto nos ha impedido captar las bellezas creadas por el hombre bajo otros cielos, la miopía de una educación que pretendía darnos la única cultura humana" (LUBAC, 1952, p. 225) ${ }^{14}$.

b) Pero, aun sin llegar a esa crítica tan radical y definitiva, nuestros días han puesto de relieve que, a lo mejor, la construcción mesiánica de la historia puede resultar decepcionante hasta para los vencedores. Nuestra Modernidad fue claramente mesiánica: se autocomprendía como el tiempo del fin. Y es por eso muy significativo que, a finales del S. XX apareciera aquel título exitoso: El fin de la historia. Porque su autor, F. Fukuyama, ya no concibe ese fin como un cielo en la tierra, sino como una época carente de horizontes, debido a que el fin de la historia ha sido simplemente un mundo totalmente "administrado". El hombre histórico se hallaba siempre ante alternativas; el mundo administrado ya no deja alternativas: compensa la inseguridad del instinto a base de sólidas instituciones sociales. Es aquella caída en el "man" (= se) que ya denunció Heidegger: el hombre hace solo lo que "se hace"; y así cree ser libre individualmente.

Esa institucionalización de todas las formas de conducta humana crea reacciones que son instintivamente seguras y por tanto predecibles. La evolución humana parece ir hoy de lo histórico a lo no histórico; con sus leyes de entropía y demás. La historia humana ya no es hoy un sistema abierto: se ha convertido en uno cerrado con la pseudoglobalización y el mercado por encima de todas las demás alternativas.

Vale la pena citar algo del último párrafo del Fin de la historia que acabamos de mencionar. Sobre todo porque, más allá de los discutibles análisis sociopolíticos del autor, ese párrafo final resulta hoy lo más significativo del libro y lo que menos atención suscitó entonces:

"El fin de la historia será un momento muy triste... La voluntad de arriesgar la propia vida por una meta abstracta, la lucha ideológica a escala global que

\footnotetext{
${ }^{14} \mathrm{Y}$ unos datos que ilustran esa bárbara ceguera: En solo el siglo XVII fueron vendidos 2.750.000 esclavos; se calcula que, en total hubo unos 20.000.000 de esclavos y murieron unos 50 millones antes de llegar a serlo (MOLTMANN, 2004, p. 278). A cambio de lo cual se produjo, a corto plazo, la mayor acumulación de riqueza jamás soñada. Pero, siglos después, los explotados están siendo sustituidos por los excluidos, a los que ya no se les necesita ni para explotarlos.
} 
exigía audacia, coraje, imaginación e idealismo, será reemplazada por el cálculo económico, la interminable resolución de problemas técnicos..., y la satisfacción de las sofisticadas demandas de los consumidores. No habrá arte ni filosofía... Lo que siento dentro de mí y que veo en otros alrededor mío es una fuerte nostalgia de la época en que existía la historia...Tal vez esta misma perspectiva de siglos de aburrimiento al final de la historia, servirá para que la historia nuevamente se ponga en marcha" (subrayados míos) (FUKUYAMA, 1992, p. 132).

Sorprende la coincidencia de este final con el mundo que describía la célebre novela de A. Huxley: Un mundo feliz. Y sorprende aún más que lo que en Huxley quería ser una protesta crítica, en Fukuyama aparezca como una constatación resignada. Como si la ilusión mesiánica de la Modernidad nos hubiera llevado a una deshumanización triste y aburrida, llena de nostalgia por algo perdido, y donde no hay más sentido de la vida que el consumo cada vez más sofisticado. El "salvaje" (de la novela de Huxley) se revela, allí como aquí, más humano que el presunto "civilizado" de Fukuyama ${ }^{15}$.

c) Y, como buscando una compensación inconsciente de esos fracasos, nuestra ultimísima hora se caracteriza por ser hora de la felicidad impuesta y proclamada. La sociedad del mercado global y el consumo contínuo quiere hacernos creer que hemos hallado lo que buscábamos y que no hay alternativas. Es conocido de sobra cómo ese mesianismo moderno secularizado ha intentado eludir la decepción postmoderna proclamando una especie de felicidad artificial, y de obligación de sentirnos felices. Títulos significativos (y hermanos) como El deber de ser feliz y La felicidad paradójica lo dicen todo ${ }^{16}$. Se recoge ahí esa obsesión de la modernidad por desautorizar aquella religiosidad que hablaba del mundo como "valle de lágrimas", aunque con la esperanza de que existe un "después de este destierro". Quizá lo del valle de lágrimas no era una forma de masoquismo religioso, como se pretendía, sino una experiencia humana universal que se refleja en los tres puntos que acabo de comentar: víctimas, falsa libertad y falsa felicidad.

Esa fe en el progreso ha sustituido la providencia divina (o mejor formulado: la acción del Espíritu Santo ${ }^{17}$ ) por la evolución biológica. Hace ya más de 50 años, Guardini intuyó algo importante: con la Modernidad, el hombre tiene poder sobre las cosas pero no tiene poder sobre su poder (GUARDINI, 1963, p. 117-119).

\footnotetext{
${ }^{15}$ Menos mal que este autor sospecha que, al final, ese mismo aburrimiento podría volver a despertarnos. Pero que no sea para caer en un nuevo milenarismo profano.

${ }^{16}$ Debo remitir para esto al Cuaderno 166 de "Cristianismo y justicia" (Nada con puntillas), con referencias a Pascal Bruckner y a G. Lipovetsky, autores de los dos títulos citados en el texto. ${ }^{17}$ El término tan usado (divina providencia) me parece en realidad poco cristiano porque desconoce la total autonomía de este mundo donde Dios no es una causa más y no interviene en él como un agente extrínseco, sino solo procurando trabajar nuestros corazones.
} 
En efecto: frente a esa crítica moderna del "valle de lágrimas", la postmodernidad ha tenido el valor de comprender que las calamidades del mundo de hoy son obra del hombre, no de Dios: armamentismo, endeudamiento, biotecnología, destrucción del planeta..., son obras nuestras que se escapan de nuestras manos; el estilo de vida del primer mundo no es universalizable; el mercado obliga a las naciones pobres a abandonar su economía de subsistencia y pasar al monocultivo, y eso para provecho del mercado mundial, no para ellas...

Hoy son ya muchos los que reconocen que nuestro sistema económico es la bestia del Apocalipsis, pero no estamos dispuestos a cambiarlo. La convivencia se está volviendo un imposible tanto a niveles sociales como individuales: los políticos no están para dialogar sino para pelearse. Y la intimidad física se entrega mucho antes que la intimidad espiritual. Con lo cual la primera pierde encanto y la segunda se vuelve imposible y la sexualidad pasa a ser una especie de caza mayor de la cual se podrán sacar algunos trofeos, pero no se saca compañía ni convivencia. Renace así la visión hobbiana del hombre como solo "un lobo para el hombre" y, consecuencia de ella, la admiración por el Leviatán tiránico, creador de unidad.

¿Soy muy negativo? Podría escribir otras tantas páginas proclamando logros innegables de nuestra historia: la supresión de la esclavitud, la declaración de derechos humanos universales, la intuición de tantos socialismos de que necesidades básicas humanas (salud, educación, alimento...) no pueden quedar al arbitrio de negociantes privados sino mayoritariamente en manos de unos poderes públicos bien controlados; más el descubrimiento de la igualdad entre varón y mujer sin menoscabo de su diversidad, la necesidad de acabar con todos los racismos, la toma de conciencia cada vez mayor de la enfermedad de nuestro planeta, la superioridad de la democracia sobre el autoritarismo. Soy bastante teilhardiano en la concepción global de que la evolución (aunque con mil tanteos y fracasos) marcha hacia delante y tiene lo que Teilhard llamaba "un omega". Pero si hubiese comenzado proclamando todo eso, habría olvidado dos cosas fundamentales: que todos esos logros no están ni plenamente aceptados ni totalmente realizados. Y, sobre todo, habría olvidado la obligación fundamental de un cristiano: hablar siempre y juzgarlo todo desde las víctimas. A mí en particular me va bastante mejor de lo antes escrito; pero no considero que mi punto de mira sea el universal ni el adecuado para juzgar nuestra hora histórica ${ }^{18}$.

En todo caso, la positividad no consiste en ocultar lo negativo. $Y$ hablando desde el Espíritu (alque ahora vamos a pasar) creo que el verdadero optimista

\footnotetext{
${ }^{18}$ Me permito remitir para esto a "Sabiduría de la cruz. Manifiesto para un pesimismo cariñoso", recogido en la tercera edición de Este es el hombre. Estudios sobre identidad cristiana y realización humana (Madrid 1986), aunque el punto de arranque de sus reflexiones fue la llamada "transición española".
} 
es el capaz de repetir pacíficamente aquel aparente disparate del entrañable hermano Casaldáliga: "de derrota en derrota hasta la victoria final"...

\section{La cristología del Espíritu como cristología del mesianismo}

Antes hablé de esa pérdida de la comprensión de la identidad cristiana como identidad mesiánica. Quisiera ahora sugerir la hipótesis de que ese olvido (o falsificación) del mesianismo, típico de tantos cristianos, está relacionado con otro olvido o falsificación de la cristología. Últimamente se está hablando mucho de la necesidad de una "cristología del Espíritu", una necesidad que, a su vez, parece brotar del olvido del Espíritu en casi toda la teología occidental ${ }^{19}$.

\subsection{Logos y Pneuma}

La cristología del Espíritu no se opone a la cristología del Logos sino que más bien la completa ${ }^{20}$. Si la del Logos es una cristología del ser, podemos decir que la cristología del Espíritu es la del actuar de Jesús (por eso se encuentra más en los evangelios sinópticos). Por eso, aunque sean inseparables, la cristología del Logos apunta más a la fe en Jesucristo, mientras que la cristología del Espíritu apunta más al seguimiento de Jesús. Dios se revela en Cristo, pero actúa por el Espíritu, al que Urs von Balthasar califica como “el desconocido más allá de la Palabra” (BALTHASAR, 2004, p. 89).

Al mantener ambas cristologías como inseparables, se salvaguarda esa tesis fundamental de la reflexión sobre la Trinidad que la tradición designó como "perichôresis"; y que la traducción habitual (circumincesión) deja tan oscura como el mismo original griego. Podríamos hablar de una especie de "copresencia" ilativa de las hipóstasis trinitarias de modo que ninguna está ni actúa nunca sola, sino siempre unida a las otras $\operatorname{dos}^{21}$.

\subsection{El Bautismo como "anunciación"}

Esa cristología del Espíritu debe brotar de la experiencia bautismal de Jesús. En los sinópticos, la perícopa del bautismo de Jesús tiene un ca-

\footnotetext{
${ }^{19}$ Sobre este déficit pneumatológico remito al último capítulo de Herejías del catolicismo actual. (Madrid, 2013).

${ }^{20}$ No percibir esto es, en mi opinión, el fallo del libro de R. Haight (Jesús símbolo de Dios), lleno de tantas sugerencias útiles por otro lado. Pero el autor parece creer que la cristología del Logos es "pura poesía" y que solo la del Pneuma es verdadera cristología.

${ }^{21} \mathrm{Y}$ esto ha de afirmarse más allá de la clásica discusión escolástica sobre si las acciones de las Personas en la Trinidad son propias o solo "apropiadas". Una discusión que no hace ahora al caso.
} 
rácter programático equivalente al que tiene el pasaje de la anunciación en Lucas. De modo que podríamos hablar ahora de una "anunciación pneumatológica".

En efecto: en la anunciación lucana, el ángel proclama que el mismo comienzo del ser de Jesús es obra de Dios y no humana, como luego proclamará también el prólogo de Juan $(1,14)$ : el Logos de Dios se hace fragilidad humana. En el bautismo hay otra proclamación y otro "descenso" del Espíritu, precisamente cuando va a comenzar el obrar de Jesús. Por eso ahora no se anunciará solo la realeza y la filiación divina de Jesús (como hace el ángel de la anunciación) sino además la complacencia de Dios que mira más bien a ese obrar. Quizás por eso, Mateo no se contentó con reducir el anuncio del bautismo a solo Jesús ("Tú eres mi Hijo"), sino que amplía ese anuncio también para los lectores ("Este es mi Hijo"), que habrán de seguir ese obrar de Jesús.

Y bien: ese actuar de Jesús es precisamente el que le llevará hasta la cruz. Hoy por suerte, y gracias a la investigación crítica, tenemos la certeza de que la crucifixión de Jesús fue una consecuencia histórica de su vida y no una especie de necesidad metafísica de la justicia de $\operatorname{Dios}^{22}$.

\subsection{En los escritos joánicos}

Juan, que no narra el bautismo de Jesús, hace decir al Bautista que Jesús es aquel sobre el que vio posarse al Espíritu (Jn 1,33). Y su evangelio (que presenta un Jesús mucho más glorioso que humano y parece narrar una pasión casi indolora), acuña sin embargo una categoría propia y fundamental, que vincula el mesianismo de Jesús con la cruz: "la hora" de Jesús ${ }^{23}$ que es, precisamente, la hora de la cruz y la de la glorificación.

La respuesta de Jesús a su madre en Caná de Galilea no significa que aún no ha llegado la hora de realizar milagros (pues va a hacer uno inmediatamente), ni es una evasiva o un poner a prueba sino que, como suele pasar en Juan, late allí una teología dialéctica muy típica de este evangelista. Como si Jesús dijera a María: me pides algo que tiene que ver con mi carácter de Mesías; pero recuerda que el verdadero mesianismo no está en los milagros sino en la cruz. Juan coincidirá aquí plenamente con el texto de Pablo citado al comienzo de este artículo.

Y una intuición semejante puede encontrarse en la primera carta de Juan: lo que allí se anuncia con entusiasmo al comenzar la carta es que "aquello que era desde siempre, y ahora hemos tocado y os manifestamos" es "la

\footnotetext{
${ }^{22}$ No es posible entrar ahora en la valoración de toda la explicación expiatoria de la muerte de Jesús, centrada sobre todo en la obra Cur Deus homo de san Anselmo. Remito para ello al capítulo 12 de La Humanidad Nueva.

${ }^{23}$ Cf Jn 2,4; 7,30; 12,23; 13,1...
} 
Palabra de la vida" (con artículo en el original): si la Palabra designa naturalmente al Logos, la Vida puede ser una alusión al Espíritu que es "dador de vida" según el Credo. De hecho, esta carta contiene dos bloques destinados a Dios: Dios es Luz y Dios es Amor. La luz la da la palabra y el amor da la vida. Y de hecho, la primera vez que aparece expresamente el Espíritu en esta carta, es cuando se cierra la que sería primera parte y pasamos al segundo bloque (cap. 4): "permaneceremos en la Luz si cumplimos su mandamiento de amor por el Espíritu que Él nos dio" (Jn 3,24) ${ }^{24}$.

\subsection{Los "misterios" de su vida}

La cristología del Espíritu es pues una cristología de esa praxis mesiánica de Jesús que es la que le llevó a la cruz. Hay que valorar el hecho de que Tomás de Aquino intente intuitivamente hacer algo de eso, hablando no meramente de episodios sino de "misterios" de la vida de Jesús (STh III, q. 31 y siguientes), aunque la pérdida del horizonte pneumatológico le lleve más a justificar esos misterios que a aprender de ellos ${ }^{25}$.

Volviendo a cosas ya escritas, en La Humanidad Nueva (capítulo 2) elegí, para comentar esa praxis mesiánica de Jesús, tres campos que facilitan mucho el acceso a una cristología del Espíritu: Jesús y la ley (el Espíritu es libertad), Jesús y los marginados (el Espíritu es amor), Jesús y el Templo (el Espíritu es universalidad: "derramado sobre toda carne"). He destacado luego en otros lugares que las dos palabras que en los evangelios más se dicen para caracterizar esa praxis de Jesús son: "se admiraban de su libertad" y "se le conmovieron las entrañas": esa síntesis de libertad y amor tiene también claros armónicos pneumatológicos ${ }^{26}$.

\section{5 "Sacerdote, profeta, rey"}

También, desde una cristología pneumatológica creo que puede comprenderse bien, y recuperarse, el triple oficio asignado por la tradición a Jesús (Profeta, Sacerdote, Rey) que, en sus orígenes, parece haber tenido importancia grande, y hoy se nos ha desdibujado bastante y significa menos. Una palabra rápida sobre ellos.

Aunque Jesús a veces es caracterizado por la gente como profeta por su modo de actuar, el título cristológico supera esa calificación. Schillebeeckx resumía toda la praxis de Jesús en el título de Profeta escatológico. Esa re-

\footnotetext{
${ }^{24}$ Hablé de esto un poco más en el capítulo 2 (Revolución en la idea de Dios) de El rostro humano de Dios. De la revolución de Jesús a la divinidad de Jesús. Santander, 2015).

25 "Utrum conveniens fuerit" es la pregunta con que Tomás se acerca a los diversos episodios de esa praxis de Jesús. Ver La Humanidad Nueva, p. 615 (de la edición citada).

${ }^{26}$ Algo parecido cabría decir del modo jesuánico de ejercer la autoridad, y de las expulsiones de demonios. Remito a los capítulos 3 y 4 de Otro mundo es posible... desde Jesús. Santander 2010.
} 
ferencia al final de la historia pone más de relieve los aspectos mesiánicos de este oficio: Jesús no es profeta simplemente porque denuncie u obre actos milagrosos sino porque toda su praxis es una praxis del "Reinado de Dios": esa expresión que resume toda su predicación y que tiene un significado, a la vez, histórico y metahistórico.

De modo parecido, Jesús no es sacerdote como un caso más (ni que fuera el mejor) de un concepto universal de sacerdocio, sino al revés: destruyendo ese concepto y recuperándolo transformado en la praxis de una vida entregada que constituye el único culto que "llega hasta el cielo". La carta a los hebreos, que comienza también con un prólogo calificable como cristología del Logos ("finalmente nos habló en el Hijo"), se despliega después con una praxis de misericordia y credibilidad que es la que constituye a Jesús en verdadero sacerdote ${ }^{27}$. Y esa praxis culmina en la cruz, cuando Jesús "entregó su vida por el Espíritu", como subraya el autor (Heb 9,14).

Finalmente, el oficio de rey es el más mesiánico, pero no como añadiendo este carácter a los anteriores sino como llevándolos a su plena realización. Jesús reina "mesiánicamente": rechazando ese título cuando el pueblo quiere coronarlo, para que quede luego proclamado sobre su misma cruz. Otra vez como el Mesiás crucificado.

Otra vez, pues, ese triple oficio es un resumen de la praxis mesiánica de Jesús que es el contenido de una cristología del Espíritu.

\subsection{La universalidad de Cristo}

Y una última observación. Esta cristología del Espíritu es la que más debería afrontar el tema de la universalidad de Cristo, al tratar el tema tan actual de las religiones de la tierra: el Espíritu ("derramado sobre toda carne") es factor de universalización. Y, por eso, es lo que el cristianismo debe aportar al encuentro, convivencia y trabajo conjunto con las otras religiones (o mejor cosmovisiones) de la historia que, solo después, podrá convertirse en verdadero diálogo. Comenzar por el diálogo sin praxis común, y llevar ahí solo una cristología del Logos, da lugar a malentendidos y sospechas de superioridad que llevaron a muchos simplistas (por razones aparentemente éticas) a negar la encarnación de Dios y la divinidad de Jesús, o a reclamar una pluralidad de encarnaciones en otras religiones (como si estas pudieran aceptar tranquilamente la idea de encarnación). Y olvidando además que la encarnación que profesa el cristianismo no es solo individual, sino de alguna manera universal ${ }^{28} \mathrm{o}$, en lenguaje neotestamentario "recapituladora" (Ef 1,14).

\footnotetext{
${ }^{27}$ Remito para esto al capítulo dedicado a la carta a los hebreos (la revolución en el culto) de El rostro humano de Dios (2015).

${ }^{28}$ Cf. Gaudium et Spes 22 (citando a Tertuliano): "por la encarnación Dios se unió de alguna manera con todos los hombres".
} 
Por tanto, la encarnación no es una propiedad privada que hace al cristianismo superior a la hora de dialogar. Es solo una buena noticia que el cristianismo tiene que comunicar. Y, vista desde una cristología del Espíritu, lleva el encuentro con las religiones a la busca de una praxis común que sea una praxis mesiánica. Como en todos esos encuentros, eso dará lugar inevitablemente a aceptaciones y rechazos ${ }^{29}$. En cualquier caso, eso permitiría comprender que la universalidad de Cristo es una universalidad de múltiples, no de uniformidad. Y llevaría al cristianismo a aportar al encuentro de las religiones su identidad mesiánica: de manera que pueda haber encuentros en el seguimiento de Jesús (que es llamada válida para todos los hombres) aunque no los haya en la fe en Jesucristo.

A eso lo he calificado otras veces como "antropocentrismo pneumatológi-

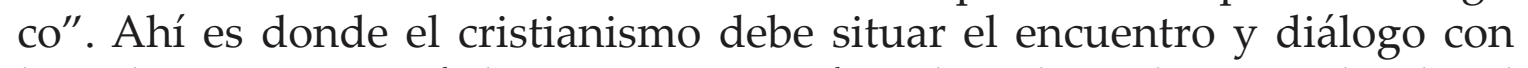
las religiones: no qué dice tu cosmovisión sobre el ser de Dios (donde, al menos según el cristianismo, hasta el que diga más verdad solo dirá una mentira más pequeña $\left.{ }^{30}\right)$, sino cómo me pide mi cosmovisión que me comporte con el ser humano: de una manera liberadora (mesiánica) o de una manera indiferente o insolidaria. Precisamente en esos encuentros es donde pueden nacer vínculos que luego convertirán el diálogo en verdadero encuentro y no en confrontación o disputa.

\subsection{Las consecuencias de un olvido}

Sólo por haber perdido la cristología del Espíritu se pudo enseñar que Cristo, en los 40 días después de la Resurrección, explicó a los apóstoles cómo habían de actuar y lo dejó todo atado y bien atado. En una visión así, Pentecostés sobra. Los Hechos de los Apóstoles y la historia muestran exactamente lo contario: la Iglesia se fue formando poco a poco por la acción del Espíritu. El seguimiento de Jesús, que es su llamada fundamental, dejó de ser entonces un seguimiento creativo ${ }^{31}$ y se convirtió en una mera mímesis (imitación) que parecía querer repetir lo que Cristo hizo entonces, en lugar de buscar lo que Cristo haría hoy ${ }^{32}$. Y es evidente que esto segundo está ligado a lo primero pero, a la vez, lo incultura. La increíble barbaridad de Gregorio XVI (en la encíclica Mirari vos), al rechazar lo de la Iglesia "siempre necesitada de reforma", alegando que Dios, por su amor a la Iglesia, la hizo ya lo más perfecta posible, resulta desde aquí muy comprensible aunque no deje de ser muy lamentable.

\footnotetext{
${ }^{29}$ Como ocurre también, dentro del cristianismo, con mil comunidades de las llamadas "evangélicas" pero que son profundamente conservadoras y antimesiánicas.

${ }^{30}$ Según la clásica enseñanza del IV concilio de Letrán (1215). "non tanta similitudo quin magis dissimilitudo" (DH, n. 806)

31 "caminar con" Él, que es lo que significa la palabra akolutheô.

${ }^{32} \mathrm{Y}$, aunque no es este momento de tratar el tema del ministerio de la mujer, sí podemos decir que es desde esa premisa desde donde debemos abordarlo: no si Jesús llamó a mujeres sino si las llamaría hoy.
} 
Desde otra óptica, que afecta más directamente a nuestro tema y que tiene carácter de reacción contra el olvido anterior, el (grave) error de Joaquín de Fiore fue creer que la era del Espíritu sucedía a la era de Cristo cuando, en realidad, van juntas (pero De Fiore las conoce como separadas...). Cuando el imperio ha desaparecido y esa idea de la Iglesia como realización total del Reino va resquebrajándose, aparece Joaquín de Fiore, anunciando una inminente "era del Espíritu" y recuperando un cierto mesianismo desde la Trinidad: hay tres épocas del mundo (que en realidad no se suceden sino que se entrelazan): la era del Padre creador, la del Hijo redentor y la del Espíritu transformador. El error de De Fiore fue considerarlas como sucesivas. Pero su visión positiva de la historia tiene además una raíz cristológica, pues Joaquín la vincula a las tres venidas de Cristo: en la carne, en el Espíritu (la que él anuncia) y en la gloria. Su error (que otra vez falsifica la idea del mesianismo) resulta ser, además, un primer aviso sobre la falta de pneumatología en la iglesia Occidental ${ }^{33}$. Y si antes hemos puesto un ejemplo posterior de este desenfoque en el rechazo de la reforma de la Iglesia, ahora podemos ponerlo en el detalle de que Hernán Cortés, para conquistar México, pondrá en las banderas una cruz con la legenda de Constantino: "con esta señal venceremos". Estamos otra vez como Pedro en su primera respuesta a Jesús...

\section{Conclusión: hacia el verdadero mesianismo.}

La cristología del Espíritu puede ayudarnos a entender que las ambigüedades vistas en las dos primeras partes de este artículo (la de la palabra Mesías y la de la historia), están relacionadas entre sí. La cruz pertenece ahora a la praxis y a la vida de Jesús (recordar otra vez Heb 9,14), mientras que la explicación satisfaccionista de la muerte de Jesús podía prescindir totalmente de su vida. Pero la cruz es también inseparable de la Resurrección, por la que Cristo entra en la vida misma de Dios.

La noción cristiana de mesías se convierte entonces en muy distinta de la noción judía: no solo porque en esta última no cabía la cruz, sino porque el mesianismo cristiano implica además la Resurrección y la Divinidad del Mesías y, con ello, la revelación de Dios como amor y solidaridad que se abajan hasta la miseria humana y que no responden a la maldad humana destruyendo al hombre, sino soportando en su mismo ser esa maldad: es el grito sorprendido de Pablo de que Dios "no escatimó a su propio Hijo sino que lo entregó por nosotros". Se abre así paso también a la universalidad del Mesías que ahora ya no está prometido a solo un pueblo sino a toda

${ }^{33}$ La obra de De Lubac, La posteridad espiritual de J. de Fiore, permite seguir los pequeños rebrotes de esa esperanza milenarista. 
la humanidad (realizando así la misión de aquel pueblo que no había sido elegido para sí mismo sino para ser "luz de las gentes").

El escándalo y locura de Pablo, se convierten ahora en "sabiduría y fuerza de Dios" (1Cor 1,24). El mesianismo está estrechamente unido a la escatología: Pannenberg habla, por eso, de la Resurrección como "el fin de la historia anticipado en ella". Y toda pretensión mesiánica, o toda edad de oro futura (sea religiosa o laica) desconectada de la escatología, se convierte en lo que R. Niebuhr describía como: “Un Cristo sin cruz conduce a hombres sin pecado hacia un reino de Dios sin juicio" (MOLTMANN, 2004, p. 247). Sus resultados son hoy en día ya más que previsibles.

Y si la historia es el lugar donde el Mesías fue crucificado y desde donde el Mesías resucitó a la vida misma de Dios, entonces volverse a la historia no es olvidarse de Dios sino al revés: es volverse a Dios. $\mathrm{Y}$ volverse a Dios no es olvidar la historia sino al revés: es encararse con la historia. Volverse a la historia solo podrá ser un olvido de Dios si antes ha olvidado que esta historia a la que nos volvemos está marcada por la muerte y Resurrección del Mesías.

Hablé al comienzo del Mesías Jesús como "el esperado que destruye las esperanzas". El mesianismo cristiano (jugando ahora a la dialéctica de Hegel de tesis-antítesis-síntesis) es un mesianismo recuperado como "síntesis" desde la destrucción del mesianismo humano. Y, como escribí antaño "esa destrucción no acontece meramente por la renuncia a los aspectos esplendorosos y triunfalistas de éste, sino que es expresión de algo más hondo: al hombre que vive en la espera de un 'mesías' (que le arregle las cosas), se le niega esa esperanza y en lugar de ella se le pone el mundo entre las manos" (GONZÁLEZ FAUS, 2016, p.309)

Desde aquí quiero concluir, para ser lo más gráfico posible, comparando la letra de dos cantos cristianos bastante conocidos. La misa salvadoreña tiene un precioso sanctus que canta a Dios como Señor no solo del universo, sino "de toda la historia, que acompaña a nuestro pueblo y que vive en nuestra lucha". La orientación y la verdad mesiánica de esas palabras, no hace falta comentarla. Sin embargo esa ilusión se sobrepasa en el canto final de la misa: "cuando el pobre crea en el pobre construiremos la fraternidad". Parece haber ahí una promesa de éxito intrahistórico que sobrepasa lo cristianamente mesiánico: porque, muy probablemente, el pobre nunca llegará a creer del todo en el pobre y, aunque así fuera, los pobres no son, por desgracia, los únicos protagonistas de esta historia cruel.

Hay otra canción titulada "Pequeñas aclaraciones" que comienza con un "cuando" como el de la misa salvadoreña: "cuando el pobre nada tiene y aún reparte, cuando un hombre pasa sed y agua nos da..." y se va prolongando en mil acciones de ese tipo para concluir no con una promesa de humanidad construida, sino con la explicación de que entonces "va Dios 
mismo en nuestro mismo caminar". De eso es de lo que estamos seguros. Si luego en ese caminar se construye la tierra sin males o el paraíso, o si solo llegamos (con lenguaje de msr. Romero) a poner "remiendos" y no remedios, es cosa que no depende solo de nosotros sino de otras mil libertades que son también sujeto de la historia.

Esa forma de presencia de Dios en la historia es la base de todo mesianismo y de toda auténtica espiritualidad cristiana. Es una gran fuerza, pero deja abierto el fin de la historia, el cual nunca está asegurado: simplemente porque cada conquista (como también cada fracaso) nunca es definitiva sino que ha de ser corroborada y asumida por las generaciones siguientes que son tan libres como la nuestra ${ }^{34}$.

Así lo deja claro también el Nuevo Testamento, donde hay, a la vez, textos que auguran un final feliz de la historia y textos que profetizan un final calamitoso. Entre los primeros, 1Cor 15,24-28 describe una serie de liberaciones progresivas, a la que Dios responde con la liberación final de la muerte. Son textos de los que podemos decir que presentan la voluntad de Dios sobre la historia.

Pero hay también textos más pesimistas, como los llamados discursos apocalípticos de Jesús (Mc 13 y paralelos) que podrían reflejar el resultado de la desobediencia del hombre y que ocupan un lugar muy significativo: son, temporalmente hablando, las últimas palabras de Jesús, mientras que su primer anuncio había sido el del reinado de Dios cercano.

Ninguno de esos dos grupos de textos son profecías infalibles, sino posibilidades abiertas: no se escriben porque vayan a suceder necesariamente, sino porque pueden suceder. Simplemente coinciden con un dato decisivo de la teología de Ireneo de Lyon, ya en el siglo II: para él es evidente que Dios creó al hombre "para que creciera y progresara" (IRÉNÉE, 1965, p. $498)^{35}$. Pero es también claro que lo que llamamos pecado original y pecado del mundo constituyen como una enfermedad o un peligro que amenaza constantemente con corromper al progreso humano.

Aclaremos que también es evidente que, ante una enfermedad, la reacción buena no es la de eliminar al paciente sino la de procurar sanarlo. Desde aquí quizá podemos resolver todas las ambigüedades y ambivalencias

\footnotetext{
${ }^{34} \mathrm{Si}$ el lector conoce la obra-antología Vicarios de Cristo: los pobres en la teología y espiritualidad cristianas (Barcelona 2018) encontrará allí testimonios impresionantes de veinte siglos de cristianismo, de gentes que vivieron y trabajaron desde la convicción creyente de que hay que conquistar la esperanza en la venida del reino de Cristo mediante el esfuerzo por participar activamente en todos los movimientos de libertad, de justicia y de paz. Porque, aunque el éxito no sea cierto, lo innegable es que sin justicia social no puede haber paz y sin paz no podremos salvar la tierra.

35 "plasmavit Deus hominem in augmentum et incrementum" escribe aludiendo al Génesis (Adv. Haer., IV, 11, 1).
} 
que hemos ido encontrando desde el inicio de este estudio, trasladando a su verdadero lugar el significado de la palabra mesías con que abrimos estas reflexiones.

Mesías significa ungido, no significa victoria. Impregnado y empapado del Espíritu de Dios, como esos ungüentos que dan agilidad y facilidad de movimientos. Y eso es lo que quisimos destacar al decir que cristiano significa mesiánico: el cristiano está llamado y capacitado por su fe para trabajar en la construcción de la historia, no está necesariamente llamado al éxito de ese trabajo ${ }^{36}$.

Y si esto es lo que hay que decir al cristiano, al no cristiano occidental comprometido en construir un paraíso en la tierra, pero que se niega a reconocer la matriz cristiana de su compromiso, habría que recordarle este detalle que, Habermas ha reconocido varias veces: "no creo que, como europeos, podamos entender seriamente conceptos como el de moralidad, libertad y emancipación..., sin apropiarnos de la sustancia de la idea de 'historia de la salvación' de procedencia judeocristiana" ${ }^{\prime 37}$.

Y para dar una visión más global de nuestro futuro, así como la teología de la liberación (expresión actual del mesianismo) ha llegado a todo el mundo desde el extremo occidental latinoamericano, también desde el extremo oriente debería llegar a todo el mundo la teología "indocristiana" de la India. Creo que se puede hablar con tranquilidad de una inspiración del Espíritu ( $i$ “derramado sobre toda carne"!) en los Upanișads, leídos en serio y no desde la superficialidad con que nosotros hemos querido hacer "un yoga de consumo". En este encuentro entre los dos extremos, quizás Europa (como más cercana a los lugares originarios del cristianismo) debería aportar a ambos el recuerdo y la teología de la cruz. Ya ha ocurrido algo de eso con la teología de la liberación. No sé si tanto con el indocristianismo. Sin embargo, el gran precursor de este cristianismo, el benedictino H. Le Saux (Abishiktananda) escribió un día en su diario: "Viernes Santo. La cruz. Aquí el purusha ya no es suficiente para explicar el misterio de Jesús y del hombre" 38 .

\footnotetext{
${ }^{36}$ Puedo remitir aquí al capítulo 15 (El enigma insoluble de la historia) de Fe en Dios y construcción de la historia. Madrid 1998.

${ }^{37}$ Nachmetaphysisches Denken, p. 23. El olvido de esas raíces teológicas ha sido reconocido también por nombres como W. Benjamin o T. Adorno ("pensar las cosas desde la redención" etc.). ${ }^{38}$ La montée au fond du coeur, p. 417. Purusha es un término de la tradición hindú que intenta expresar lo más sublime del espíritu humano.
} 


\section{Referencias}

ANSELMO, S. Cur Deus Homo (Por qué Dios se hizo hombre). In Obras Completas de San Anselmo - Vol. I, Madrid: BAC, 1952.

BALTHASAR, H. U. von. Ensayos de teología: Spiritus Creator. Madrid: Encuentro, 2005. v. 3.

BRUCKNER, P. La euforia perpetua. Sobre el deber de ser feliz. Barcelona: Tusquets, 2008

CONCILIO ECUMENICO VATICANO II. Constituición pastoral Gaudium et Spes: sobre la Iglesia y el mundo de hoy. 1965.

CONDORCET, J.-A.-N. de C. Bosquejo de un cuadro histórico de los progresos del espiritu humano. Madrid : Editora Nacional, 1980.

DENZINGER, E. El magisterio de la Iglesia. Manual de los símbolos, definiciones y declaraciones de la Iglesia en materia de fe y costumbres. Barcelona: Herder, 1963

EURÍPEDES, Tragédias I: El Cíclope, Alcestis - Medea - Los Heraclidas - Hipólito - Andrómaca -Hécuba. Madrid: Editorial Gredos, 1991.

FUKUYAMA, F. El fin de la Historia y el último hombre: la interpretación más audaz y brillante de la historia presente y futura de la humanidad. Barcelona, Editorial Planeta, 1992.

GONZALEZ FAUS, J. I. La humanidad nueva: ensayo de cristologia. Madrid: EAPSA, 1974.

GONZALEZ FAUS, J. I. Este es el hombre. Estudios sobre identidad cristiana y realización humana. Madrid: Ediciones Cristiandad, 1987.

GONZÁLEZ FAUS, J. I. Fe en Dios y construcción de la historia: Madrid: Trotta, 1998.

GONZÁLEZ FAUS, J. I. Vicarios de Cristo: los pobres en la teología y espiritualidad cristianas : antología comentada. Barcelona: Centre d'Estudis Cristianisme i Justícia, 2005.

GONZALEZ FAUS, J. I. Nada con puntillas fraternidad en cueros: la lucha por la justicia en una cultura nihilista. Cuadernos (Cristianisme i Justícia), Barcelona, p. 1-32, n. 166, fev., 2010.

GONZALEZ FAUS, J. I. Otro mundo es posible... desde Jesús. Santander: Sal Terrae, 2010.

GONZÁLEZ FAUS, J. I. Herejías del catolicismo actual. Madrid: Trotta, 2013.

GONZALEZ FAUS, J. I. El rostro humano de Dios: de la revolución de Jesus a la divinidad de Jesus. Santander: Sal Terrae, 2015.

GONZALEZ FAUS, J. I. La humanidad nueva: ensayo de cristologia. 10. ed. Madrid: Sal Terrae, 2016.

GONZALEZ FAUS, J. I. ¿Hay una teología de la historia?. Revista Latinoamericana de Teología. San Salvador, p. 305-327, n. 108, Set./Dez., 2019.

GREGÓRIO XVI, Papa. Carta Encíclica Mirari Vos. 1832. 
GUARDINI, R. El ocaso de la Edad Moderna: un intento de orientación. Madrid: Ediciones Guadarrama, 1963.

HAIGHT, R. Jesús, símbolo de Dios. Madrid: Trotta, 2007

HABERMAS, J. Nachmetaphysisches Denken: philosophische Aufsatze. Frankfurt: Suhrkamp, 1992

HUXLEY, A. Un mundo feliz. Madrid: Unidad Editorial. 1999.

IRÉNÉE DE LYON. Contre les hérésies. Paris: Cerf, 1965. v. 2.

LIPOVETSKY, G. La felicidad paradójica. Ensayo sobre la sociedad del hiperconsumo. Barcelona: Editorial Anagrama, 2007.

LE SAUX, H. (ABHISHIKTÂNANDA, Svâmi). La Montée au fond du coeur. Le journal intime du moine chretien-sannyasi hindou (1948-1973). Introduction et notes de R. Panikkar. Paris: OEIL, 1986.

LUBAC, Henri de. Catholicisme: les aspects sociaux du dogme. 5. ed. Paris: Cerf, 1952.

LUBAC, H. de. La posteridad espiritual de Joaquín de Fiore I: De Joaquín a Schelling. Madrid: Editorial Encuentro, 2011..

LUBAC, H. de. La posteridad espiritual de Joaquín de Fiore II: De Saint-Simon a nuestros dias. Madrid: Editorial Encuentro, 2011.

MOINGT, J. L'homme qui venait de Dieu. Paris: Cerf, 1993.

MOLTMANN, J. La venida de Dios: escatologia cristiana. Salamanca, Ediciones Sígueme, 2004.

SCHILLEBEECKX, E. Jesus: la historia de un viviente. Madrid: Cristiandad, 1983.

TOMAS DE AQUINO, Santo. Suma de Teología: III: Parte II-II. Madrid: BAC, 1990.

Artículo sometido en 31.08.2020 y aprobado en 09.12.2020.

José Ignacio González Faus sj es Doctor en Teología en la Universidad Austríaca de Innsbruck (1968). Exprofesor de la Facultad de Teología de Cataluña y de la UCA de San Salvador. Antiguo responsable académico del centro de estudios «Cristianismo y Justicia» de Barcelona. Orcid.org/0000-0002-7536-201X. E-mail: gfaus@fespinal.com

Dirección: Centre Borja - Llaceres, 30 08173 SANT CUGAT DEL VALLÈS

Barcelona 